\title{
Variation of snail's abundance in two water bodies harboring strains of Pseudosuccinea columella resistant and susceptible to Fasciola hepatica miracidial infection, in Pinar del Río Province, Cuba
}

\author{
Alfredo Gutiérrez/ , Dagmar F Hernandez*, Jorge Sánchez \\ Laboratorio de Malacología, Instituto "Pedro Kourí”, Apartado 601 Marianao 13, Ciudad de la Habana, Cuba \\ *Facultad de Biología, Universidad de la Habana, Cuba
}

\begin{abstract}
The abundance of freshwater snails in two rural sites of Pinar del Río, Cuba, which harbor Pseudosuccinea columella susceptible and resistant to miracidia of Fasciola hepatica was followed for one year. Susceptible snails were found in the most anthropic site (IPA) whereas the resistant population inhabited the most preserved one (El Azufre). Only two snail species coexisted with P. columella at IPA site (Physa cubensis and Tarebia granifera) while five species were found at El Azufre, including an endemic from that province (Hemisinus cubanianus). Populations of both resistant and susceptible snails showed stable densities throughout the year, although the susceptible strain attained higher abundance. The highest densities were observed in April-May 2004 for the susceptible population whereas the resistant strain attained its highest abundance in January 2004. No record of Fossaria cubensis was made and the thiarid T. granifera occurred only at low densities. One of the sampled sites (IPA) meets all the conditions for the first report of $\mathrm{P}$. columella naturally infected with larvae of $\mathrm{F}$. hepatica.
\end{abstract}

Key words: Pseudosuccinea columella - Lymnaeidae - freshwater snails - Fasciola hepatica - abundance - diversity - resistance susceptibility - Cuba

In Cuba two Lymnaeid snails, Fossaria cubensis and Pseudosuccinea columella, act as intermediate hosts in the life cycle of the digenean parasite Fasciola hepatica, although only the former has been found naturally infected. Nonetheless, high infection rates for $P$. columella have been observed in laboratory exposures. In addition, natural infection has been reported in Argentina, Brazil, and Australia (Ueta 1980, Boray et al. 1985, Oliveira et al. 2002, Prepelitchi et al. 2003). Recently, several populations of $P$. columella were reported to show no susceptibility (i.e. resistance) to miracidia of $F$. hepatica and some studies were conducted in order to compare various traits between resistant and susceptible snails under laboratory conditions (Gutiérrez et al. 2002, 2003a, b, Calienes et al. 2004). However, due to the disappearance of resistant populations from their original sampling sites, no study including resistant $P$. columella had been conducted so far under natural conditions. One site recently surveyed (El Azufre) harbors a population of resistant snails which seem to thrive in a more stable environment (Calienes et al. 2004). The present study was conducted with the objective of providing data on the variation of abundance throughout a year of resistant (for the first time) and sus-

+Corresponding author. E-mail: pcolumella@yahoo.es Received 3 February 2005

Accepted 30 September 2005 ceptible populations under natural conditions and to observe the possible association between their densities and those of other snail species present in their habitats.

The work was carried out in the village of San Andrés, La Palma municipality, Pinar del Río province. Two sampling sites were selected (Fig. 1): El Azufre, a spring source which shows little signs of human activity, and IPA, a small canal whose waters are drained from a dam located close to the IPA (Instituto Politécnico Agropecuario) school and where sheep and cows are seen grazing everyday. Both sites are separated $1.85 \mathrm{~km}$ from each other. The samplings were performed by collecting snails with a sieve and forceps, always by the same collector during 15 min; the abundance was measured as the number of snails collected per 15-min sampling. A total of 22 and 20 samplings were made in IPA and El Azufre respectively from July 20, 2003 to June 10, 2004. The snails were identified and counted in their corresponding sampling site.

The snail species found in the two study sites are as follows. IPA - P. columella (susceptible strain), Physa cubensis, and Tarebia granifera; El Azufre - P. columella (resistant strain), P. cubensis, T. granifera, Hemisinus cubanianus, Drepanotrema lucidum, and Eupera cubensis.

The abundances of species at each sampling are presented in Figs 2 and 3. In IPA (Fig. 2) P. columella shows the most stable populations as well as the highest abundances for most of the study period compared to the other two species. The highest $P$. columella densities were found in April-May 2004. T. granifera showed the lowest densities, with peaks only in October and November 2003. 


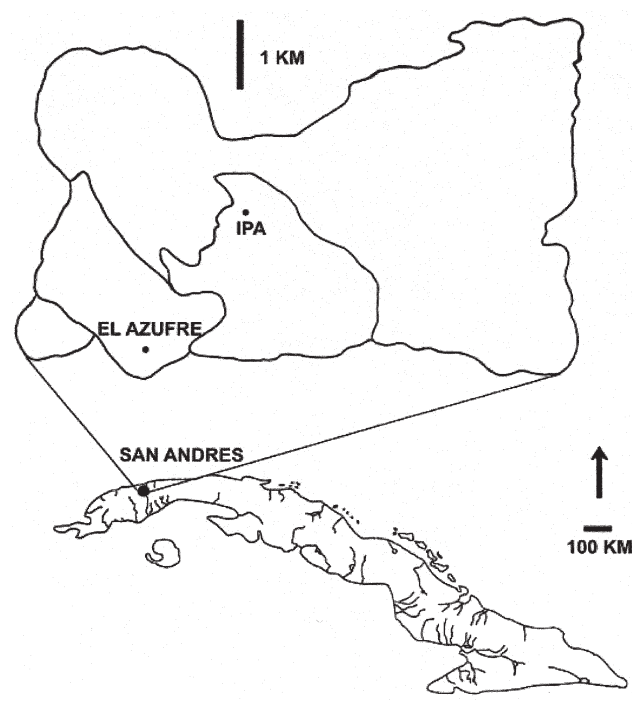

Fig. 1: map of the San Andrés Village showing the two sites selected for a one-year sampling study.

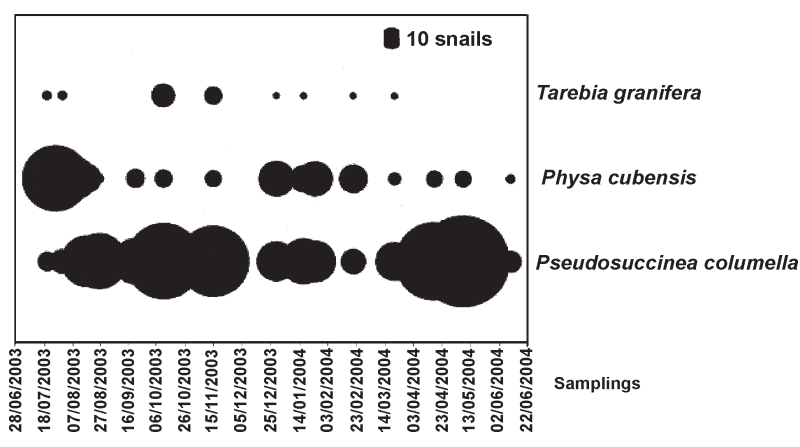

Fig. 2: one-year variation of abundances of three freshwater snail species at the IPA sampling site, San Andrés Village, Pinar del Río, Cuba. The diameter of each circle represents the number of snails per 15 min sampling.

In El Azufre (Fig. 3) the population of P. columella is also stable during the study year, and its stability is comparable only to $H$. cubanianus, since all other species showed an intermittent occurrence. The abundance of resistant $P$. columella was lower compared to the abundance attained by the susceptible strain present in IPA, the highest densities ( 25 snails/15 min sampling) being observed in January 2004 (nine times lower than the maximum densities of susceptible $P$. columella in IPA). $T$. granifera showed low densities compared to P. columella and $H$. cubanianus.

Previous laboratory life-history studies involving susceptible and resistant strains of $P$. columella indicate that susceptible are best suited than resistant snails to adapt to the same environmental conditions, suggesting a possible cost related to resistance (Gutiérrez et al. 2002). In fact, the first two resistant populations disappeared from their collecting sites a few years after being found due to human disturbance. La Palma population was reported in 1996 and has not been observed since 1999, Babiney popu-

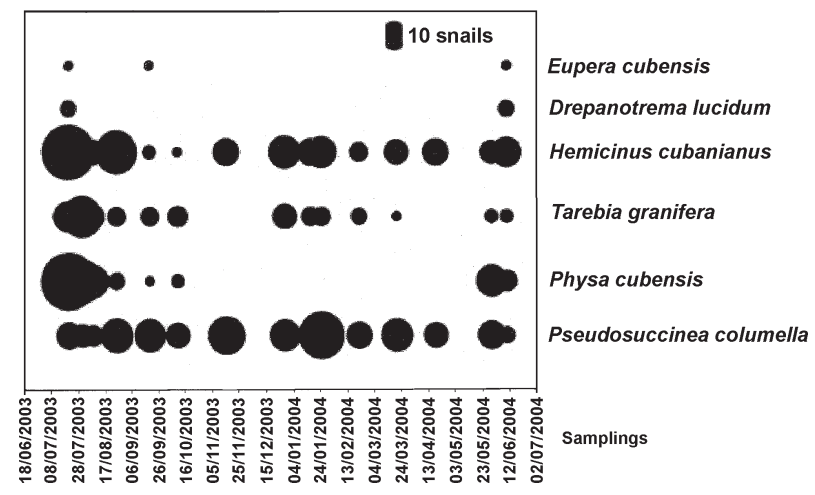

Fig. 3: one-year variation of abundances of six freshwater snail species at the El Azufre sampling site, San Andrés Village, Pinar del Río, Cuba. The diameter of each circle represents the number of snails per 15 min sampling.

lation was reported in 1998 and disappeared in 2000 (personal observations). The results of this study show that the resistant population can actually persist in certain types of habitats, like those showing little signs of human activity as El Azufre, although their densities are by far lower than the abundances attained by susceptible snails in IPA site.

Two interesting results are worth mentioning: (1) in spite of the frequent occurrence of $F$. cubensis in most of the habitats of Pinar del Rio province, no snail of this species was found during the whole study in any of the sites; (2) the prosobranch $T$. granifera occurs only at low densities in both sites and does not seem to interfere with the other species. This thiarid is known to displace other snails in numerous habitats where it is introduced (Perera et al. 1994, 1995, Gutiérrez et al. 1997). A previous study in a rural area of Pinar del Río province had reported a negative association between $F$. cubensis and $P$. columella, suggesting that both lymnaeids do not usually co-occur at comparable densities. The same study indicated that $T$. granifera could affect the densities of all snail species present in the habitat except those of $P$. columella and $C$. fluminea.

The dominance of $P$. columella observed in this study suggests that this species should play a role as intermediate host of $F$. hepatica in this particular region. One of the localities sampled in the present study (IPA) meets all the conditions necessary for the transmission of the parasite (there is a relatively big grazing sheep herd and some cows, plenty of susceptible snails and bovine fasciolosis in the surrounding area). The first $P$. columella snails naturally infected in Cuba could be probably reported at this locality in the future.

\section{REFERENCES}

Boray JC, Fraser GC, Williams JD, Wilson JM 1985. The occurrence of the snail Lymnaea columella on grazing areas in New South Wales and studies on its susceptibility to Fasciola hepatica. Aust Vet J 62: 4-6. 
Calienes AF, Fraga J, Pointier JP, Yong M, Sanchez J, Coustau C, Gutiérrez A, Théron A 2004. Detection and genetic distance of resistant populations of Pseudosuccinea columella (Mollusca: Lymnaeidae) to Fasciola hepatica (Trematoda: Digenea) using RAPD markers. Acta Trop 92: 83-87.

Gutiérrez A, Perera G, Yong M, Fernandez J 1997. Relationships of the prosobranch snails Pomacea paludosa, Tarebia granifera and Melanoides tuberculata with the abiotic environment and freshwater snail diversity in the central region of Cuba. Malacological Review 30: 39-44.

Gutiérrez A, Pointier JP, Fraga J, Jobet E, Modat S, Perez RT, Yong M, Sanchez J, Loker ES, Théron A 2003a. Fasciola hepatica: identification of molecular markers for resistant and susceptible Pseudosuccinea columella snail hosts. Exp Parasitol 105: 211-218.

Gutiérrez A, Pointier JP, Yong M, Sanchez J, Théron A 2003b. Evidence of phenotypic differences between resistant and susceptible isolates of Pseudosuccinea columella (Gastropoda: Lymnaeidae) to Fasciola hepatica (Trematoda: Digenea) in Cuba. Parasitol Res 90: 129-134.

Gutiérrez A, Yong M, Perera G, Sanchez J, Théron A 2002. Fasciola hepatica (Trematoda: digenea): its effect on the life history traits of Pseudosuccinea columella (Gasteropoda:
Lymnaeidae) an uncommon interaction. Parasitol Res 88 : 535-539.

Oliveira S, Fujii T, Filha E, Martins A 2002. Ocorrencia de Lymnaea columella Say, 1817 infectada naturalmente por Fasciola hepatica (Linnaeus, 1758), no vale do Ribeira, São Paulo, Brasil. Arq Inst Biol São Paulo 69: 29-37.

Perera G, Yong M, Ferrer JR, Gutiérrez A, Sánchez J 1994. Importancia de Tarebia granifera en el control de una población introducida de Biomphalaria peregrina en Cuba. Rev Cubana Med Trop 46: 20-24.

Perera G, Yong M, Ferrer J, Gutiérrez A, Sánchez J 1995. Ecological structure and factors regulating the population dynamics of the freshwater snail populations in Hanabanilla lake, Cuba. Malacological Review 28: 63-69.

Prepelitchi L, Kleiman F, Pietrokovsky SM, Moriena RA, Racioppi O, Alvarez J, Wisnivesky-Colli C 2003. First report of Lymnaea columella Say, 1817 (Pulmonata: Lymnaeidae) naturally infected with Fasciola hepatica (Linnaeus,1758) (Trematoda: Digenea) in Argentina. Mem Inst Oswaldo Cruz 98: 889-891.

Ueta M 1980. Estudo morfométrico da concha de Lymnaea columella SAY, 1817 (Mollusca, Gastropoda, Pulmonata). Rev Soc Bras Med Trop 13: 119-141. 